\title{
Journal of

\section{Efektifitas Media Promosi Kesehatan Audio Visual Lagu Cuci Tangan Terhadap Pelaksanaan Cuci Tangan 6 Langkah Pada Anak}

\author{
James Criony \\ Sekolah Tinggi Ilmu Kesehatan Indonesia Maju \\ Jl. Harapan nomor 50, Lenteng Agung-Jakarta Selatan 12610 \\ Email: james.criony@gmail.com
}

\section{Editor: AN}

Hak Cipta:

(C)2022 Artikel ini memiliki akses terbuka dan dapat didistribusikan berdasarkan ketentuan Lisensi Atribusi Creative Commons, yang memungkinkan penggunaan, distribusi, dan reproduksi yang tidak dibatasi dalam media apa pun, asalkan nama penulis dan sumber asli disertakan. Karya ini dilisensikan di bawah Lisensi Creative Commons Attribution Share Alike $\mathbf{4 . 0}$ Internasional.

\section{A B S T R A C T}

Introduction: Hand washing is one of the personal hygiene steps taken to prevent disease. According to WHO, only $33.7 \%$ of children in the world have the habit of washing their hands, while according to the Indonesian Ministry of Health in 2016 there are only about $17 \%$ of Indonesian children behaved properly and properly. One of the efforts that can be done to overcome these problems is by promoting the health of audiovisual media.

Objectives: This study aims to determine the effectiveness of audio-visual health promotion media using the song let's wash hands on the implementation of 6 steps of handwashing in children.

Method: This study uses a quasi-experimental method with a one-group pretest-posttest design. The sample in this study was 30 children aged 8-10 years in Cilodong District.

Result: The results of the sample paired t-test with a correlation value of $0.000<0.005$, the average value of the pretest and posttest of 30 respondents is $-15,667$ and 66,67 this value shows the difference between before the respondent is given treatment and after the respondent is given treatment. The difference is between -18.87183 to -12.46150 .

Conclusion: There is an effect of health promotion on audiovisual media, let's wash hands on the implementation of the 6 steps of washing hands in children. Based on these results, it is known that the audio-visual media of the song let's wash hands is effective in increasing children's abilities in implementing the 6 steps of good and correct hand washing.

Keywords: audio-visual media, hand washing, health promotion 


\section{Pendahuluan}

Kelompok usia anak memiliki risiko tinggi untuk menderita penyakit akibat infeksi karena tubuh imun atau daya tahan tubuh masih rentan terkena infeksi dan bakteri. Kebanyakan permasalahan kesehatan pada usia anak berkaitan dengan Personal Hygiene. Mencuci tangan merupakan salah satu langkah personal hygiene yang dilakukan untuk mencegah penyakit akibat infeksi. ${ }^{1}$ Keterbatasan pengetahuan mengenai pelaksanaan personal hygiene cuci tangan pada anak secara ideal terbilang masih kurang. Kebiasaan buruk dengan tidak cuci tangan atau jarang cuci tangan ini menyebabkan gangguan pada pencernaan anak. Menurut data WHO hanya ada setidaknya $13,7 \%$ anak di dunia yang berkebiasaan cuci tangan yang baik dan benar, sedangkan menurut Kemenkes RI 2016 hanya ada 17\% anak Indonesia yang berkebiasaan mencuci tangan dengan baik dan benar. Kurangnya informasi dalam mencuci tangan menyebabkan anak kurang memperhatikan perilaku cuci tangan. Dampak dari kurang dilaksanakannya kebiasaan cuci tangan adalah penyakit seperti diare, ISPA (Infeksi Saluran Pernafasan Atas), cacingan dan demam tifoid, hal ini disebabkan bibit penyakit akan lebih mudah masuk ke dalam tubuh apabila tangan dalam keadaan kotor. ${ }^{2}$

Salah satu upaya yang dapat dilakukan untuk mengatasi permasalahan tersebut adalah dengan melakukan promosi kesehatan menggunakan media audio visual pada anak. Media Audio Visual merupakan media yang sangat menarik yang dapat menyampaikan pesan dan informasi secara audio dan visual. ${ }^{3}$ Dalam memberikan stimulus terhadap perubahan perilaku pada sasaran, media audio visual memberikan kontribusi yang sangat besar untuk hasil yang lebih optimal. Karena mengandung unsur yang dapat di dengar dan dilihat kemampuan media audio visual dikatakan lebih baik dan lebih menarik karena panca indera yang paling banyak menyalurkan pengetahuan ke otak adalah mata (kurang lebih $75 \%$ sampai $87 \%$ ); dan $13 \%$ sampai $25 \%$ pengetahuan diperoleh atau disalurkan melalui indera yang lain. ${ }^{4}$

Tujuan dari penggunaan media audio visual adalah untuk mengembangkan kemampuan kognitif dengan memberikan rangsangan berupa gambar bergerak dan suara, serta menyampaikan pesan untuk mempengaruhi sikap dan emosi dalam format yang lebih menarik dan meningkatkan keyakinan terhadap perubahan kognitif dapat dipercepat. Menurut teori kognitif perubahan perilaku Albert Bandura, proses mengamati dan meniru perilaku dan sikap orang lain sebagai model merupakan tindakan belajar, dengan mengamati jauh lebih efisien dari pada pembelajaran dengan mengalami langsung. ${ }^{5}$

Menurut Adventus, 2019 dalam Buku Ajar Promosi Kesehatan Aplikasi teori ini adalah bahwa apabila seseorang melihat suatu rangsangan dan ia melihat model bereaksi secara tertentu terhadap rangsangan itu, maka alam khayalan atau imajinasi orang tersebut akan mempengaruhi perilakunya. Pada teori Bandura juga disebutkan bahwa proses belajar terjadi melalui interaksi dari lingkungan, dan perilaku yang diamati. ${ }^{6}$ Keberhasilan proses pembelajaran pada anak tergantung kepada komponen pembelajaran. Media audio visual merupakan salah satu komponen dari proses pembelajaran. ${ }^{7}$

Berdasarkan studi literatur yang dilakukan oleh Nur Ridha Sasmitha 2020 dengan judul Health Education About Clean and Healthy Living Behavior (PHBS) To Increased Knowledge of School Age Children: Systematic Review menyimpulkan bahwa Pendidikan kesehatan dengan menggunakan media audio visual sangat dianjurkan untuk digunakan karena tekniknya sederhana, tidak memerlukan banyak alat dan bahan, mudah dijangkau serta metode dan media yang menarik dan dapat diterapkan pada anak usia sekolah. Salah satu media audio visual yang 


\section{Journal of

dapat digunakan sebagai media penyampai pesan pendidikan kesehatan kepada anak anak adalah dengan media audio visual lagu kesehatan anak. ${ }^{8}$ Lagu adalah salah satu media audio yang menstimulasi indera pendengaran dalam proses pembelajaran. Media ini mengajarkan siswa untuk bernyanyi menggunakan syair-syair yang sesuai dengan materi yang diajarkan. ${ }^{9}$ Oleh karena itu penelitian ini menggunakan media audio visual lagu ayo cuci tangan yang diciptakan oleh peneliti sendiri yang akan di uji efektifitasnya dalam proses pemberian pendidikan kesehatan cuci tangan 6 langkah pada anak.

\section{Metode}

Jenis Penelitian ini adalah penelitian Eksperimen Semu (Quasi Experiment), dengan pendekatan rancangan desain one group pretest-posttest design yang dilakukan untuk mengetahui perbedaan perilaku mencuci tangan yang baik dan benar pada kelompok anak antara sebelum dan sesudah dilakukan promosi kesehatan menggunakan media visual lagu "Ayo Cuci Tangan". Sampel penelitian berjumlah 30 orang dengan metode total sampling. Populasi Studi dalam penelitian ini adalah anak anak di Kelurahan Kalibaru Kecamatan Cilodong.

Gambar 1. Pola Penelitian One Group Pretest-Posttest Design

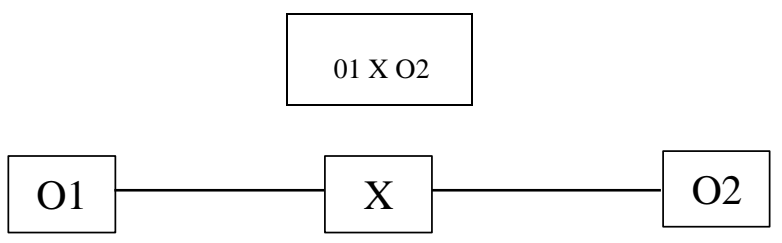

Keterangan :

O1 adalah Nilai pre-test, untuk mengetahui kemampuan anak dalam pelaksanaan PHBS sebelum dilakukan perlakuan.

$\mathrm{X}$ adalah Perlakuan dengan menggunakan media audio visual dan metode eksperimen.

$\mathrm{O} 2$ adalah Nilai post-test, untuk mengetahui kemampuan anak sesudah diberikan perlakuan edukasi menggunakan media audio visual.

Pada desain penelitian ini tes yang dilakukan sebanyak dua kali, yaitu sebelum dan sesudah diberikan perlakuan eksperimen. Tes ini menggunakan instrumen kuisioner. Tes yang dilakukan sebelum mendapatkan perlakuan disebut pretes. Pretes diberikan pada kelas eksperimen (O1). Setelah dilakukan pretes peneliti memberikan perlakuan berupa pembelajaran 6 langkah cuci tangan yang baik dan benar dengan menggunakan media audio visual dengan lagu ayo cuci tangan, lalu pada tahap akhir peneliti memberikan posttest (O2) dengan pertanyaan yang sama. Hasil pretest dan postest ini yang menjadi bahan uji efektifitas media audio visual lagu ayo cuci tangan terhadap pelaksanaan cuci tangan 6 langkah pada anak. dengan mengunakan media audio visual lagu cuci tangan. Peneitian ini telah lulus uji etik di Komisi Etik Penelitian Kesehatan dengan surat keterangan, nomor: 1797/Sket/KaDept/RE/STIKIM/VIII/2021.

\section{Hasil}

Hasil Uji independent sample t-test dari 30 respondent berusia 8-10 tahun adalah sebagai berikut : 


\section{Journal of

Tabel 1. Nilai rata-rata Uji Sample Paired t-test

\begin{tabular}{cccccc}
\hline Pengukuran & Mean Pretest & Mean Postest & $\boldsymbol{N}$ & Range Std. Deviation & $\begin{array}{c}\text { Range Std. Error } \\
\text { Mean }\end{array}$ \\
\hline Pretest-Postest & 51,00 & 66,67 & 30 & 15,67 & 0,539
\end{tabular}

Pada tabel diatas diperlihatkan hasil ringkasan deskriptif statistik dari kedua sampel atau data pretest dan postest. Nilai rata pretest sebelum diberikan perlakuan dengan menggunakan media Audio Visual lagu "Ayo Cuci Tangan" dari 30 responden adalah sebesar 51,00 sedangkan nilai rata-rata postest setelah diberikan perlakuan dengan menggunakan media Audio Visual lagu "Ayo Cuci Tangan" dari 30 respondent 66,67. Dari output SPSS ini diketahui adanya peningkatan nilai rata rata sebelum diberikan perlakuan (pretest) dan setelah diberikan perlakuan (postest). Sedangkan pada tabel kedua dari uji sample paired t-test menjelaskan hubungan korelasi atau hubungan antara kedua data atau variable yakni pretest dan postest dalam hal ini adalah korelasi person product moment. Pada output ke dua diketahui nilai signifikansi sebesar 0,000 artinya nilai signifikansi ini lebih kecil dari 0,005 sebagaimana dasar pengambilan keputusan dalam uji korelasi karena nilai signifikansi lebih kecil dari 0,005 maka indikasinya ada hubungan antara sebelum respondent diberikan perlakuan dengan media audio visual lagu "Ayo Cuci Tangan" (pretest) dan setelah respondent mendapatkan perlakuan dengan menggunakan media audio visual lagu “Ayo Cuci Tangan” (postest).

Tabel 2. Uji Korelasi Sample Paired t-test

\begin{tabular}{cccc}
\hline Pengukuran & $\mathrm{N}$ & Correlation & Sig. (2-tailed) \\
\hline Pretest-Postest & 30 & 0,858 & 0,000 \\
\hline
\end{tabular}

Pada tabel ke 2 uji Paired Sample t-test menjelaskan ada atau tidaknya perbedaan antara pretest sebelum responden diberikan perlakuan dan postest setelah responden diberikan perlakuan pada tabel ini juga menjelaskan berapakah skala interval nilai rata rata responden sebelum diberikan perlakuan dan sesudah di berikan perlakuan .

Tabel 3. Uji Sample Paired Differences

\begin{tabular}{|c|c|c|c|c|c|c|c|c|}
\hline \multirow{3}{*}{ Pengukuran } & \multicolumn{5}{|c|}{ Paired Differences } & \multirow{3}{*}{$t$} & \multirow{3}{*}{$d f$} & \multirow{3}{*}{$\begin{array}{l}\text { Sig }(2 \\
\text { tailed })\end{array}$} \\
\hline & \multirow[t]{2}{*}{ Mean } & \multirow[t]{2}{*}{$\begin{array}{l}\text { Std.Deviati } \\
\quad \text { on }\end{array}$} & \multirow{2}{*}{$\begin{array}{l}\text { Std. Error } \\
\text { mean }\end{array}$} & \multicolumn{2}{|c|}{$\begin{array}{c}\text { 95\% Convident interval } \\
\text { Of The Diffrence }\end{array}$} & & & \\
\hline & & & & lower & upper & & & \\
\hline $\begin{array}{c}\text { Pretest- } \\
\text { Postest }\end{array}$ & $-15,667$ & 8,584 & 1,567 & $-18,872$ & $-12,461$ & $-9,997$ & 29 & 0,000 \\
\hline
\end{tabular}

Pada output ketiga diketahui nilai mean sebesar -15,667 nilai ini menunjukan selisih antara mean pretest dengan mean postest pada output pertama yaitu 51,00-66,67 $=-15,667$ selisih perbedaan tersebut antara -18,87183 sampai dengan -12,46150. Kemudian untuk nilai signifikansi pada ouput ke 3 sebesar 0,000 maka dapat disimpulkan bahwa terdapat perbedaan yang signifikan antara hasil pretest anak anak sebelum diberikan perlakuan pendidikan kesehatan menggunakan audio visual lagu ayo cuci tangan dan postest setelah diberikan pendidikan kesehatan melalui audio visual lagu ayo cuci tangan. Karena sebagaimana dasar pengambilan keputusan Jika nilai Sig $(2$ tailed $)<0,05$ maka terdapat perbedaan yang signifikan antara hasil pretest responden sebelum diberikan perlakuan dengan media audio visual lagu 


\section{Journal of

"Ayo Cuci Tangan" dan Setelah diberikan perlakuan dengan menggunakan media audio visual lagu "Ayo Cuci Tangan".

\section{Pembahasan}

Berdasarkan hasil yang didapat dalam penelitian "Efektitas Media Promosi Kesehatan Audio Visual Lagu Ayo Cuci Tangan Terhadap Pelaksanaan 6 Langkah Cuci Tangan Pada Anak" yang dilaksanakan dengan menguji kemampuan anak terhadap pelaksanaan cuci tangan yang baik dan benar dengan menggunakan pretest dan postest pada anak usia 8-10 tahun terlihat adanya perbedaan kemampuan anak yang signifikan dalam pelaksanaan 6 langkah cuci tangan pada saat anak anak belum diberikan perlakuan pendidikan kesehatan dengan menggunakan media audio visual ayo cuci tangan (pretest) dan setelah anak diberikan pendidikan kesehatan dengan menggunakan media audio visual lagu ayo cuci tangan. Dari nilai ouput uji paired t-test yang dilakukan diketahui adanya peningkatan kemampuan anak dalam pelaksanaan cuci tangan yang baik dan benar yaitu dari hasil rata rata nilai pretest dan postest sebesar 51,00 menjadi 66,67. Kemudian menurut hasil uji korelasi yang dilakukan diketahui nilai signifikansi sebesar 0,000 artinya nilai signifikansi ini lebih kecil dari 0,005 sebagaimana dasar pengambilan keputusan dalam uji korelasi karena nilai signifikansi lebih kecil dari 0,005 maka indikasinya ada hubungan antara sebelum responden diberikan perlakuan dan setelah responden diberikan perlakuan dengan media audio visual lagu "Ayo Cuci Tangan" Selanjutnya berdasarkan uji paired t-test yang dilakukan untuk melihat adakah perbedaan sebelum responden diberikan perlakuan dan setelah responden diberikan perlakuan didapatkan hasil nilai signifikansi sebesar $0,000<0,05$ hal ini berarti terdapat perbedaan yang signifikan antara hasil pretest responden sebelum diberikan perlakuan dan setelah diberikan perlakuan.

Berdasarkan penelitian yang dilakukan oleh Parasyanti 2020 yang berjudul Pendidikan Kesehatan Cuci Tangan Pakai Sabun dengan Video Terhadap Kemampuan Cuci Tangan pada Siswa SD menunjukan hasil Sebelum diberikan pendidikan kesehatan CTPS, 24 anak dari 27 siswa $(88,9 \%)$ dalam kategori tidak mampu melakukan langkah CTPS, dan 3 anak $(11,1 \%)$ dalam kategori mampu. Setelah diberikan pendidikan kesehatan CTPS 25 anak (92,6\%) dalam kategori mampu, 2 anak $(7,4 \%)$ dalam kategori tidak mampu. Hasil uji Wilcoxon Sign Rank Test diketahui $p$-value $=0,000$ dengan $(\alpha<0,05)$, berarti ada pengaruh pendidikan kesehatan cuci tangan pakai sabun dengan media video terhadap kemampuan cuci tangan pada siswa. ${ }^{10}$

Pendidikan kesehatan dengan menggunakan media audio visual sangat efektif untuk digunakan dalam memberikan stimulus terhadap perubahan perilaku pada sasaran, media audio visual memberikan kontribusi yang sangat besar untuk hasil yang lebih optimal. Menurut Pekei 2016, Efektifitas adalah Apabila suatu program kegiatan mencapai tujuan yang optimal maka dapat dikatakan program kegiatan tersebut telah berjalan dengan efektif. Efektivitas adalah hubungan antara output dan tujuan yang dicapai. Untuk mengembangkan kemampuan kognitif media audio visual memberikan rangsangan berupa gambar dan suara untuk menyampaikan pesan yang dapat mempengaruhi perilaku dengan format media yang lebih menarik sehingga perubahan kognitif seorang individu dapat dipercepat. ${ }^{11}$ Berdasarkan teori kognitif perubahan perilaku Albert Bandura, proses mengamati dan meniru perilaku dan sikap orang lain sebagai model merupakan tindakan belajar, dengan mengamati jauh lebih efisien dari pada pembelajaran dengan mengalami langsung..$^{5}$

Asumsi peneliti berdasarkan hasil hitung data diatas membuktikan bahwa media audio visual lagu ayo cuci tangan efektif dalam peningkatan kemampuan anak dalam pelaksanaan 6 
langkah cuci tangan yang baik dan benar. Efektifitas media promosi kesehatan dengan menggunakan media audio visual dapat mempermudah proses penyampaian dari promotor kesehatan kepada sasaran. Pendidikan kesehatan dengan menggunakan media audio visual sangat efektif untuk digunakan selain karena tekniknya sederhana, tidak memerlukan banyak alat dan bahan, mudah dijangkau serta metode dan media yang menarik dan dapat diterapkan pada anak usia sekolah. media dalam bentuk audio visual juga sangat efektif dalam meningkatkan kemampuan kognitif seseorang untuk mencapai perubahan perilaku yang diinginkan. ${ }^{12}$

Media promosi kesehatan dengan menggunakan lagu "Ayo Cuci Tangan" Efektif meningkatkan kemampuan anak dalam pelaksanaan 6 langkah cuci tangan yang baik dan benar. Promosi kesehatan dengan menggunakan media audio visual sangat efektif untuk digunakan dalam memberikan stimulus terhadap perubahan perilaku sasaran, media audio visual memberikan kontribusi yang sangat besar dalam merubah kemampuan anak dalam pelaksanaan 6 langkah cuci tangan yang baik dan benar Media Audio Visual Lagu Ayo Cuci Tangan dapat dijadikan alternatif dalam pemberian pendidikan kesehatan kepada anak khususnya dalam pelaksanaan 6 langkah cuci tangan yang baik dan benar. ${ }^{13}$ Berdasarkan penelitian mulai tanggal 9-23 Agustus di Jalan Swadaya Kelurahan Kalibaru wilayah kerja UPTD Puskesmas Cilodong dengan menguji 30 responden dengan pretest dan postest didapatkan hasil adanya perbedaan kemampuan anak dalam pelaksanaan 6 langkah cuci tangan yang baik dan benar pada saat sebelum (uji pretest rata-rata $=51,00$ ) dan sesudah (uji postest rata-rata $=66,67$ ) diberikan promosi kesehatan dengan menggunakan media audio lagu "Ayo Cuci Tangan". Dari hasil ini diketahui adanya peningkatan nilai rata rata kemapuan anak dalam pelaksanaan 6 langkah cuci tangan yang baik dan benar.

Dari hasil uji korelasi yang dilakukan peneliti didapatkan hasil adanya hubungan peningkatan kemampuan anak sebelum dan sesudah diberikan promosi kesehatan dengan media audio visual lagu "Ayo Cuci Tangan" dengan nilai nilai Sig ( 2 tailed) 0,000< 0,05. Selanjutnya berdasarkan hasil uji sample paired t-tes yang dilakukan peneliti didapatkan hasil adanya perbedaan kemampuan yang signifikan sebelum dan sesudah diberikan promosi kesehatan dengan media audio visual lagu "Ayo Cuci Tangan" dengan nilai signifikansi sebesar 0,000 lebih kecil dari 0,05 yang mengindikasikan adanya perbedaan sebelum responden diberikan promosi kesehatan dengan media audio visual lagu "Ayo Cuci Tangan" dan sesudah diberikan promosi kesehatan dengan media audio visual lagu "Ayo Cuci Tangan". Media Audio Visual menggunakan lagu ayo cuci tangan efektif dalam peningkatan kemampuan anak dalam pelaksanaan 6 langkah cuci tangan yang baik dan benar.

\section{Kesimpulan}

Ada pengaruh promosi kesehatan Media Audio Visual lagu "Ayo Cuci Tangan" terhadap pelaksanaan 6 langkah cuci tangan pada anak. Berdasarkan hasil tersebut diketahui Media Audio Visual lagu Ayo Cuci Tangan efektif dalam peningkatan kemampuan anak dalam pelaksanaan 6 langkah cuci tangan yang baik dan benar.

\section{Konflik Kepentingan}

Peneliti menyatakan bahwa penelitian ini independen dari konflik kepentingan individu dan organisasi. 


\section{Journal of

\section{Ucapan Terima Kasih}

Terimakasih kepada seluruh pihak yang telah berkontribusi membantu proses penelitian ini.

\section{Pendanaan}

Sumber pendanaan diperoleh dari peneliti.

\section{Daftar Pustaka}

1. Anisa DN, Khusnal E. Pengaruh pendidikan kesehatan terhadap perilaku cuci tangan pakai sabun pada anak usia sekolah di SD 2 Jambidan Banguntapan Bantul. STIKES'Aisyiyah Yogyakarta; 2012.

2. Parasyanti NKV, Yanti NLGP, Mastini IGAAP. Pendidikan Kesehatan Cuci Tangan Pakai Sabun dengan Video Terhadap Kemampuan Cuci Tangan pada Siswa SD. J Akad Baiturrahim Jambi. 2020;9(1):12230.

3. Notoatmodjo S. Promosi kesehatan \& ilmu perilaku. Jakarta: Rineka Cipta; 2007.

4. Maulana I, Suryani S, Sriati A, Sutini T, Widianti E, Rafiah I, et al. Penyuluhan Kesehatan Jiwa untuk Meningkatkan Pengetahuan Masyarakat tentang Masalah Kesehatan Jiwa di Lingkungan Sekitarnya. Media Karya Kesehat. 2019;2(2).

5. Muhaimin A. Implementasi Social Learning Theory Albert Bandura dalam Pembelajaran Fikih di MTs. DDI Paria Kabupaten Wajo. Universitas Islam Negeri Alauddin Makassar; 2018.

6. Sudoyo AW, Setiyohadi B, Alwi I, Simadibrata M, Setiati S. Buku Ajar Ilmu Penyakit Dalam. Jakarta. Interna Publishing; 2009.

7. Senerat AM, Pope Z, Rydell S, Mullan A, Roger V, Pereira MA. Psychosocial and Behavioral Responses and SARS-CoV-2 Transmission Prevention Behaviors while Working during the COVID-19 Pandemic. COVID-19 Psychosoc Behav Responses. 2021;

8. Sasmitha NR, Sutria E. Health Education About Clean and Healthy Living Behavior (PHBS) To Increased Knowledge of School Age Children: Systematic Review. J Nurs Pract. 2020;3(2):279-85.

9. Margawati A, Astuti AM. Pengetahuan ibu, pola makan dan status gizi pada anak stunting usia 1-5 tahun di Kelurahan Bangetayu, Kecamatan Genuk, Semarang. J Gizi Indones (The Indones J Nutr. 2018;6(2):82-9.

10. Listiadesti AU, Noer SM, Maifita Y. Efektivitas Media Vidio Terhadap Perilaku Cuci Tangan Pakai Sabun Pada Anak Sekolah: a Literature Review. Menara Med. 2020;3(1).

11. Pekei B. Konsep dan analisis efektivitas pengelolaan keuangan daerah di era otonomi. Penerbit Taushia; 2016.

12. Selvia A, Amru DE. Efektifitas Media Promosi Kesehatan terhadap Peningkatan Pengetahuan, Sikap dan Perilaku Ibu Hamil Melakukan Kunjungan Antenatal Care. J Bidan Komunitas. 2020;3(3):132-44.

13. SYNTHIA D, Etrawati F. STUDI KUALITATIF MENGENAI RANCANGAN MEDIA PROMOSI KESEHATAN UNTUK PENCEGAHAN HIV/AIDS PADA REMAJA DI KOTA PALEMBANG. Sriwijaya University; 2021. 